\title{
DIE METALLE
}

\section{BEI DEN NATURVÖLKERN}

MIT BERÜCKSICHTIGING

\author{
PRÄHISTORISCHER VERHÄLTXISSE
}

$\mathrm{voN}$

\section{RICHARD ANDREE.}

MIT 57 A B B ILDU N G E N I M TEXT.

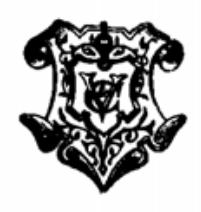

LEIPZIG,

VERLAG VON VEIT \& COMP.

1884. 
Das Recht der Herausgabe von Übersetzungen vorbehalten. 